Ward, S. and Caklais, S. (2019). "Piloting the Deployment of ISO18404 in the Construction Sector, An Approach to Organizational Transformation." In: Proc. $27^{\text {th }}$ Annual Conference of the International. Group for Lean Construction (IGLC), Pasquire C. and Hamzeh F.R. (ed.), Dublin, Ireland, pp. 203-214. DOI: https://doi.org/10.24928/2019/0174. Available at: www.iglc.net.

\title{
PILOTING THE DEPLOYMENT OF ISO 18404 IN THE CONSTRUCTION SECTOR, AN APPROACH TO ORGANISATIONAL TRANSFORMATION
}

\author{
Steven A Ward ${ }^{1}$ and Simon Caklais ${ }^{2}$
}

\begin{abstract}
Despite significant experience with lean, the construction sector still fails to grasp the nettle and cannot keep up with other sector's rates of improvement. Ad hoc deployment of tools and techniques are common, but business transformations appear extremely rare. The research approach rests upon a focused literature review, examining the concept of Lean Construction transformation in the context of culture change, together with a single case study of the world's first business to achieve certification to the Lean ISO18404 standard. Key learning points from the case study were derived by structured interviews with construction staff directly involved and by noting similarities of the lean deployment to recommendations made in the literature. It is concluded that ISO 18404 is appropriate for the construction sector and could provide a useful roadmap to those seeking business transformation. Limitations and recommendations for further work and research are offered.
\end{abstract}

\section{KEYWORDS}

ISO18404, Lean construction, organisational transformation, standardisation.

\section{INTRODUCTION}

The focus here is lean construction transformation in the context of organisation wide deployment and creation of a lean culture throughout a construction business.

The philosophy, tools and techniques of lean construction are well known. (Ansah et al. 2016) For those that apply these, the benefits are also well known. However, the industry as a whole has not adopted lean thinking and has not kept pace with the rate of improvement that other sectors have enjoyed (Barbosa et al. 2017). The existing literature is full of reasons, barriers, peculiarities of construction and excuses why this is so (Ballard \& Howell 1998; Koskela 2000). Over the last twenty years many applications of lean construction have occurred, as evidenced by the significant body of literature on the subject. However, it would appear that the vast majority of attempts to apply lean in construction are of an ad

1 Technical Director, Continuous Improvement Services, WSP, Bristol, UK +447917104399, steve.ward@wsp.com

2 Managing Director, Gilbert \& Goode, St Austell, UK +447766903418 s.caklais@ gilbertandgoode.co.uk 
hoc nature, mainly either on a project basis or maybe a narrowly focused process improvement basis. Ward (2015) based research around lean construction interventions because there were not enough data on transformations in construction available.

Standardisation is a theme central to lean and can be seen throughout its history and development. (Graupp \& Wrona 2006). The international organisation for standardisation is an independent, non-governmental international organisation with a membership of 163 national standards bodies. (ISO 2019a) In late 2015 a new management standard was published, ISO 18404:2015, that "defines the competencies for the attainment of specific levels of competency with regards to Six Sigma, Lean, and "Lean \& Six Sigma" in individuals, e.g. Black Belt, Green Belt and Lean Practitioners and their organizations." (ISO 2019b). The certification of individual's competencies to an international standard may interest the lean construction community, but the opportunity to gain organisational certification to a lean international standard is of particular interest because it may possibly assist with overcoming some of the barriers to more widespread adoption of Lean Construction. The usefulness of ISO18404 in construction as a transformation model is therefore explored.

\section{REVIEW OF RELEVANT LITERATURE}

\section{ISO18404}

A search using the term "ISO18404" returned nil results on the IGLC conference paper web page but a Google search using the term "ISO18404 Construction" returned a few relevant results, but all linked to the case study to be discussed here.

The question is whether this ISO standard can assist with construction company lean transformations; so, the term "transformation" was again used on the IGLC website. This time 79 papers were displayed. Two forms of transformation are discussed in these. The first is concerned with Koskela's Transformation Flow Value theory (Koskela 2000) and about process, but the second is about culture change and the industry uptake of lean. For clarity the latter is the focus of this paper.

Of the 79 papers, fifteen appeared related to the subject of transformational change in the construction sector and of these a further two were discounted after closer examination. The remaining papers were mainly concerned with organisational structure, roadmaps for lean transformation with clarifications of lean concepts, leadership and change by force.

\section{ORGANiSATIONAL STRUCTURE}

According to Arbulu and Zabelle (2006), temporary organisations associated with construction projects provide an advantage when seeking transformation which is contrary to the majority of literature on the subject of lean, that suggests temporary organisations are a barrier. Pekuri et (2014) discuss the need to create appropriate business models for lean construction transformation to take place, they examine the business model employed by the exemplar Toyota and compare this with usual construction business models. In the lean driven example provided, it appears that there is a clear link between lean operations, capability and strategy. They conclude that an appropriate business model is necessary for successful transformation. 


\section{ROADMAPS FOR LEAN AND CLARIFICATION OF CONCEPTS}

A common theme across several papers discusses the perceived need for a roadmap for lean construction transformations. Naney et al. (2012) provide a useful discussion on construction-sector-wide adoption of lean. They use the Hype cycle of innovation as a tool to gauge transformational success and also link the slow uptake of lean construction, to Moore's "Crossing the Chasm," technological adoption curve. (Moore 1991) This appears similar to change curve thinking (Kübler-Ross 1969). They point out that industry wide construction sector strategies for transformation are missing, and the key "Early majority group in Moore's change adoption curve need a "compelling case and/or a roadmap to follow." They conclude that for castor wide uptake of lean construction, we must learn how to bridge the gap between the early adopters and the early majority.

The further development and adoption of a lean construction maturity model is recommended by Nesensohn et al. (2014). They are not clear on why this is needed or what benefit it might bring but Sainath et al. (2018) offer another maturity matrix for lean construction based on the perceived need to provide clarity to industry of lean concepts and also to gauge progress toward achieving these. Following Naney et al such a model might help provide the missing roadmap necessary to engage the "Early Majority" of the construction sector. Nesensohn et al. (2015) build on their earlier work concerning a maturity model and offer a more complete version, they reinforce the idea that a clearer definition of lean construction and a roadmap to follow will help transformation. Ward (2015) labours unsuccessfully over a definition of lean construction but also believes it would add significant value. Leonova et al. (2017) also call for the need for clarity regarding lean concepts, adoption and definitions.

\section{LEADERSHIP}

Lean construction in the context of organisational change caused by the adoption of the lean philosophy as opposed to the adoption of tools and techniques is discussed by Pekuri et al. (2012). They highlight 5 corner-stones necessary for success as Leadership, Motivation, Competence, People and Trust. Keiser (2012) is also focused on aspects of leadership, aiming to create "High Performance Teams." (Katzenback and Smith 1993) The role of leadership in transformation is discussed by Kerem et al (2013) who show how leadership training in lean at the coal face had a positive impact on organisational change and provide practical help on the subject of what lean leadership should look like in construction. This links with Torp et al. (2018), who compare lean transformation attempts across several linked companies within the same holding group and provide a key observation that a top down approach from senior management was essential. More guidance on business transformation using a top down and bottom up method simultaneously is provided by Kalyan et al. (2018) This model has many similarities to the case study discussed in this paper below.

\section{Change by FORCE}

Citing the first obstacle to lean construction as "unwillingness to change until forced," Gehbauer et al. (2017) commendably propose transformation on a grand scale driven by 
focused collaborative research, They insist that culture change is the key as the ingrained behaviours of industry must change in order for lean to flourish. They ask 34 questions that are suggested areas for focused and collaborative research to move things forward. Of these the following questions appear linked and relevant to the subject in focus here.

- How can public authorities be helped to develop new regulations and new behaviour?

- How can it be shown that Lean is much more than a mere collection of tools?

- How can Lean be spread through education? Can a standard curriculum be developed?

- How can Lean become the norm in construction worldwide?

- How can Lean be developed from offering new concepts into a force that drives change in industry and society? How can drivers for change be identified?

\section{AN OVERVIEW OF THE REQUIREMENTS OF ISO18404}

The ISO18404 Standard (BSI 2015) can be broadly divided into two parts.

Firstly, it provides guidance on the knowledge and competencies that a person delivering lean improvements in an organization should be able to display. In the standard's appendices there are three detailed tables for differing levels of expertise named Lean Practitioner, Lean Leader and Lean Expert. The competencies include a wide range of lean skills and at Practitioner level are mainly concerned with application. At Leader level they include application, management and some training ability. At Expert level, application, management and training ability for all competencies is expected.

If an organisation has its own certified Lean Leaders or Lean Expert in place it is allowed to certify its own Lean Practitioners internally. A Lean Expert may also be an external resource if appended to the company's management system.

The second and perhaps most important part of the standard in regard to transformation describes requirements for organisational certification. To achieve certification an organisation must be able to demonstrate that:

- It has the required resources in place including an appropriate level of competent personnel, and that this competence is maintained. (competence as defined in the appendices described above)

- A clear link can be displayed between the lean deployment and company strategy with defined objectives.

- An appropriate architecture needs to be in place. For example, a reporting structure, steering groups, accountabilities and support.

- It can display structured continuous improvement with defined metrics, targets and review mechanisms. 


\title{
A LEAN CONSTRUCTION TRANSFORMATION CASE STUDY UTILISING ISO18404
}

\begin{abstract}
ABOUT THE CASE STUDY COMPANY
The company was established in 1972 and is based in Cornwall UK. They deliver a range of contracts from major projects to minor works and maintenance. In 2005 they were acquired by a registered social landlord, to expand traditional and contracting business, and also to construct the group's housing developments. They are a commercially focused contractor with a social purpose, returning any surplus profit to the parent group for reinvestment for the public good.
\end{abstract}

In 2018 turnover was approximately £25mil with around 70 employees. Growth to $£ 40 \mathrm{mil}$ is forecast in the next two years.

\section{THE COMPANY's Lean JOURNEY}

\section{The Motivation for Lean Transformation}

The managing director had experienced the benefits of lean construction whilst working as Head of Projects for a large airport authority, delivering major projects in a complex operational, logistically constrained environment.

There was a need to attack the cost base of new build housing and drive both qualitative and quantitative improvement in a structured manner. He saw the opportunity to improve productivity of the business by driving out the inherent waste in construction operations thus increasing the company's competitive advantage and delivering greater returns to the parent Group. Furthermore Cornwall, like most of the UK, suffers from a lack of skills and capacity and by working with the supply chain and offering them a platform on which they could perform and make money, more could be gained from the limited resources available and the best talent could be attracted to the company's sites. He began to encourage adoption of lean techniques within the company via knowledge transfer and in 2016 appointed a consultant to help accelerate the efforts. An initial Lean awareness workshop was held with about 20 staff. This was followed by two pilot projects predominantly using the Last Planner® System. The pilot projects yielded good results with lead time gains of around $15 \%$. The company staff and supply chain willingly adopted collaborative planning techniques as all involved could see the benefit.

After the pilot projects the company's approach to production control using elements of the Last Planner® System was standardised and applied on every live project.

Following this initial stage, the Managing Director wanted to go further but was unsure of the best route. A number of options were investigated including pursuit of the new ISO18404 standard and this route was agreed.

\section{Implementation of ISO 18404}

No company had done this before, and the path was unclear. The company approached the Construction Industry Training Board (CITB) for help and they agreed to fund the pilot project. A plan for the deployment project was formed and work started in earnest in December 2017. 
The company were already certified to other management standards such as ISO 9001, 14001 and 18001. These cover quality systems, environmental and health and safety standards respectively. They wished to create a single integrated management system, based on lean principles using the new 18404 standard.

ISO18404 requires internal staff resources that meet the competences detailed in the standard and so key personnel received training. The MD, the Head of Development, the Head of Construction and a dedicated Project Manager to oversee initial implementation were trained to Lean Leader level. Eight other key staff covering project management, site management, sales and aftercare undertook Lean Practitioner Training.

External resources were appointed that included: a professor who chaired the committee that authored the standard to provide strategic guidance relating to this and a lean construction consultant to provide lean construction specific training and act in the capacity of certified Lean Expert under the standard.

A strategy was formed that clearly linked the lean improvement efforts back to the company's corporate strategy and metrics that could be tracked. This appears in Figure 1.

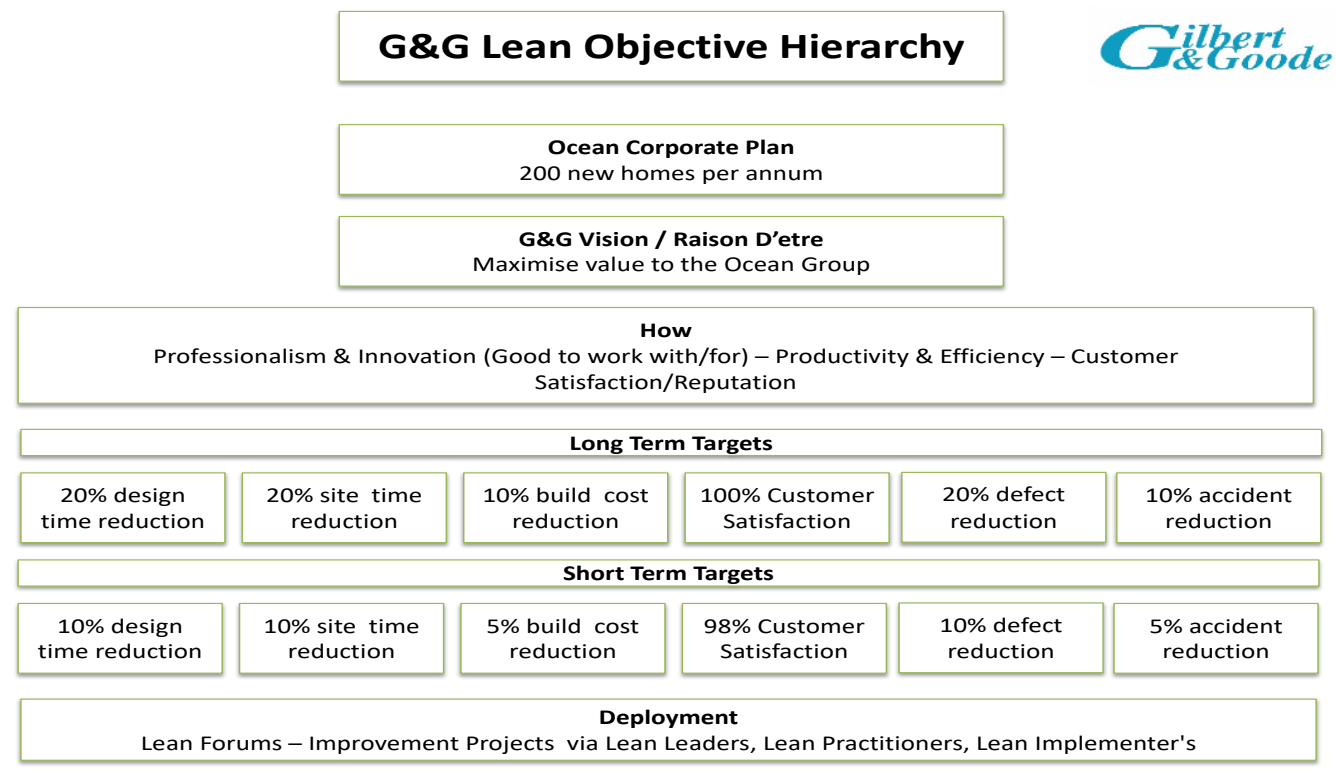

Figure 1. Lean Strategy Summary

During training a wide range of lean improvement projects were agreed covering the end to end value stream from design development and acquisition to sales and aftercare. These projects were prioritised on a single page plan and implemented according to capacity constraints, with some projects agreed but "queued". The business case for each project was weighed against its likely ability to deliver against the headline KPI's in the strategy document.

A Lean Management team, made up of the company's Lead Leaders, was created to oversee the delivery of the strategy. Six Lean improvement forums were established to support each of the KPIs and manage the improvement projects, each one being led by a 
Lean Practitioner and sponsored by a Lean Leader. This structure forms the basis of the company's continuous improvement architecture and is shown in Figure 2.

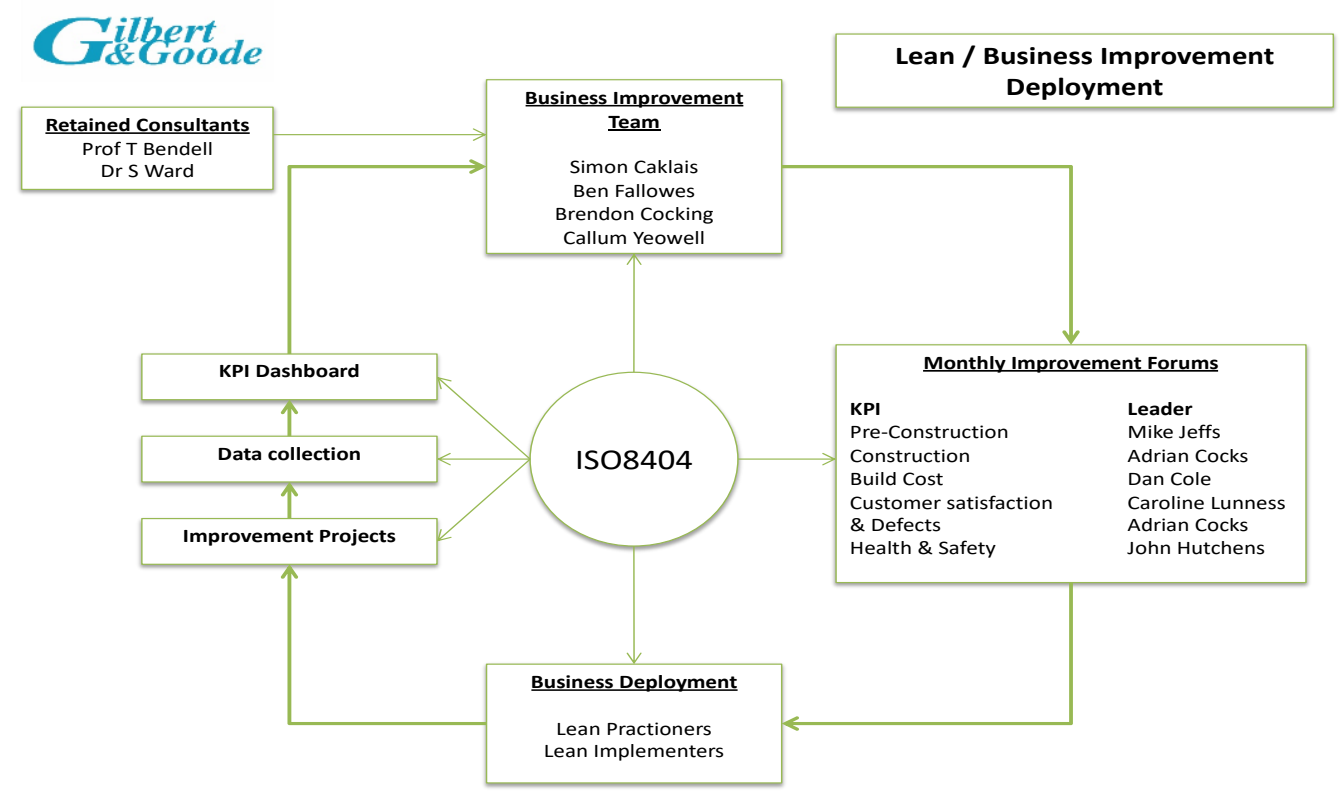

Figure 2. Architecture for Continuous Improvement

It was found that a further level of competence was required that did not exist in the standard. This level required fewer skills than Lean Practitioner, but measurable competence sought so the competencies of Lean Practitioner were cut down to a more basic level and "Lean Implementers" were trained. This served to widen the net in terms of who and how many people got directly involved in improvement efforts. A further 100 people in the business plus including key suppliers also received training at a basic level. During 2018, virtually all the company's staff contributed to business improvements in some way.

\section{Certification by The Royal Statistical Society and British Standards Institute}

Throughout 2018 the company continued to execute the agreed plan. This was led directly by the senior leadership team with consultant support. Lean Practitioners and Lean Leaders were coached in the development of their portfolios of evidence required and were examined for competence by the Royal Statistical Society, the sector scheme owners, during October 2017. The British Standards Institute was invited to audit against the ISO Standard and carried out stage one and two audits during December 2018. The registered scope of assessment was "The management and maintenance of Lean programmes when delivering construction services."

On the $9^{\text {th }}$ of January 2019 the company received certification to the new standard, the first company worldwide to achieve this.

In terms of transformation, it is not the case that every single action or process by the company is guaranteed to be lean, or that they now perform better than any other company 
of their kind. (Although they may do in time) Rather it is the case that the majority of people working in the business understand the key concept of value for the customer, are supportive to continuously improving this and have a realistic methodology for doing so.

\section{KEY LEARNING POINTS IN THE DEPLOYMENT CASE STUDY}

The following learning points were formed by a combination of direct observation, participation by the authors and by content analysis of interviews conducted with the lean Leaders and Lean Practitioners after the implementation completed.

- It was observed that initial motivation for the transformation appeared both internal and external. Internal derived from leadership vision and external from market conditions.

- Management led from the front. The ISO18404 standard at Lean Leader level requires the leader to be able to train certain lean skills. The senior management team all took part in personally training their own staff. According to the Managing Director - this was key to getting buy-in and signalling that a new, continuous improvement culture was operating.

- All staff were involved at some level and were in no doubt as to the purpose of the efforts, again supporting buy-in of the continuous improvement culture.

- A clear link was created between overall strategy and lean deployment activity.

- A clear path was available in terms of the guidance in the ISO 18404 standard, with the architecture and resources put in place to deliver and sustain the lean management system.

- There was consensus that a tangible shift in overall culture had been achieved as a result of the implementation.

- Difficulties with data capture and the ongoing management of this were a concern.

- The sequence of training could have been improved with Lean Leaders beginning before Lean Practitioners and then cascading.

- There was consensus that ISO18404 could help the construction sector but that each implementation must be tailored to individual organisational needs.

- Practical aspects like weekly planning deployment and waste walks were seen as a significant contributor to success.

- Dedicated resources for data capture \& management and also helping continued administration of the system are required.

- Implementation would have been extremely difficult without the external consultant expertise

\section{THE IMPORTANCE OF DATA}

As the standard title suggests "quantitative methods in process improvement", data collection and analysis are vital in supporting continuous improvement in a 
business. Target improvements to Key Performance Indicators (KPI's) are typically based on historic performance of the business, however the accuracy, type and format of the historic data may prove to be inadequate, especially as the focus on data capture increases within a business; meaning performance may not appear to improve on certain measures, as the data quality improves. One example in this case study was the post-handover defects reduction KPI, which appeared to get worse in the short term, as the level of detail captured increased. In addition, a number of the quality improvement projects linked to a new visual based Quality Assurance system, would take over a year to go through the project lifecycle before the improvements could be properly calculated. This also then led to a review of KPI's both based on the frequency of new data sets and also the relevance of the measures to potential changing business objectives. For example, the original time target was overall reduction in project programme time. However, as the business moved to more sales rate 'pull' delivery, the metrics for batch or cycle time had a greater relevance. In summary, the learning here is that KPIs may need to be changed or rebased as the maturity of your data increases and your understanding and application of their use evolves but the fact that measurement has become a key component of the business's continuous improvement culture, is the most important outcome.

\section{LINKS WITH LITERATURE}

In the literature review several key themes emerged and it is offered here that the case study may possibly help with the following areas.

1. The management system offers a "roadmap to follow" as recommended by Naney et al. as necessary to bridge the gap between the early adopters and the early majority on Moore's adoption curve.

2. Pekuri et al.'s five corner stones of Leadership, Motivation, Competence, People and Trust can be observed.

3. Pekuri et al's links between capability and strategy and lean operations can be observed.

4. Leadership training following Kerem et al. was evident.

5. It could be viewed that the standard provides an operational definition of lean required by Nesensohn et al. and Ward.

6. Many of Ward's "Critical Success Factors for lean Construction Intervention" (2015) are observed to have been present: e.g. Management capability, buy-in, appropriate data, collaboration with sub/c, etc.

7. Improvement activity was top down, and bottom up simultaneously as recommended by Kalyan et al.

8. Gehbauer et al. (2017) states that the industry won't change until forced. As an ISO Management system there exists a clear capability to incorporate into procurement, thus potentially accelerating the uptake of lean principles by force. The effectiveness of business improvement using other related ISO systems was explored at length by Manders (2015) who found the best performers were 
internally not externally motivated as a key success factor. This does not concur with the "change by force" approach discussed by Gehbauer et al. Possibly the right answer is that both internal and external motivators are required.

9. Five of Gehbauer et al.'s thirty-four questions are listed above, and it is thought that the adoption of an international lean standard could help answer these in a positive way.

\section{CONCLUSIONS}

In 2018, the first company in the world achieved accreditation to the new international lean standard ISO18404. This company is a Main Contractor based in South West England. This suggests that it is applicable and appropriate in construction.

Following the literature review and case study, it is offered that this new standard could provide the recommended roadmap for others to follow.

The ISO18404 standard is not perfect, but in time will be reviewed and improved. This is in line with any informed approach to standardisation. There are many other certifications and competency systems and it is likely that the 18404 standard will suffer from "not invented here" syndrome. However, it is the only standard currently available in lean that is truly global with an appropriate supportive infrastructure and has the possibility of embedment in procurement systems etc.

\section{FURTHER RESEARCH}

Sustainability of the implementation should be examined. Also, after Gehbauer et al. it is recommended that the questions below become focus areas of research linked to the further deployment of ISO 18404.

- How can Lean become the norm in construction worldwide?

- How can Lean be developed from offering new concepts into a force that drives change in industry and society? How can drivers for change be identified?

- How can public authorities be helped to develop new regulations and new behaviour?

\section{ACKNOWLEDGMENTS}

Thanks go to CITB and particularly Raquel Iredale and Nathaniel Cooke.

The Lean Leaders at Gilbert and Goode

- Ben Fallowes, Brendan Cocking and Callum Yeowell

- The Lean Practitioners at Gilbert and Goode

- Adrian Cocks, Caroline Lunness, Craig Kendall, Mike Jeffs, Mike Pelan and Steve Luck

\section{REFERENCES}


Ansah, H.A et al. 2016 “Lean Construction Tools” Proceedings of the 2016 International Conference on Industrial Engineering and Operations Management Detroit, Michigan, USA, September 23-25, 2016

Arbulu, R. \& Zabelle, T. 2006, 'Implementing Lean in Construction: How to Succeed' In:, 14th Annual Conference of the International Group for Lean Construction. Santiago, Chile, 1-. pp 553-565

Ballard, G. and Howell, G. (1998). Shielding Production: Essential Step in Production Control. Journal of Construction Engineering and Project Management, Vol. 124(1): 11-17.

Barbosa, F., Woetzel, J., Mischke, J., Ribeirinho, M.J., Sridhar, M., Parsons, M., Bertram, N. and Brown, S., 2017. Reinventing construction: a route to higher productivity. McKinsey Global Institute.

BS ISO 18404:2015 "Quantitative methods in process improvement. Six Sigma. Competencies for key personnel and their organizations in relation to Six Sigma and Lean implementation” British Standards Institute ISBN 9780580812064

Gehbauer, F. , Ballard, G. \& Leonova, M. 2017, 'How Research Can Help Transform the Construction Industry' In:, 25th Annual Conference of the International Group for Lean Construction. Heraklion, Greece, 9-12 Jul 2017. pp 293-300

Graupp, P. and Wrona, R. (2006). The TWI Workbook: Essential Skills for Supervisors. Productivity Press, New York.

Kalyan, V. , Pratap, V. \& Singh, S.C. 2018, 'Building a Lean Culture Into an Organization' In:, 26th Annual Conference of the International Group for Lean Construction. Chennai, India, 18-20 Jul 2018. pp 1101-1110

Katzenback, J.R. and Smith, D.K., (1993). The Wisdom of Teams

Keiser, J.A. 2012, 'Leadership and Cultural Change: Necessary Components of a Lean Transformation' In:, Tommelein, I.D. \& Pasquire, C.L., 20th Annual Conference of the International Group for Lean Construction. San Diego, USA, 18-20 Jul 2012.

Kerem, C. , Barak, R. , Sacks, R. \& Priven, V. 2013, 'Learning to See - Managers Working in the Gemba as Part of the Tidhar Way Training Program ' In:, Formoso, C.T. \& Tzortzopoulos, P., 21th Annual Conference of the International Group for Lean Construction. Fortaleza, Brazil, 31-2 Aug 2013. pp 957-966

Koskela, L. (2000). An exploration towards a production theory and its application to construction - PhD thesis Helsinki University of Technology, Helsinki.

Kübler-Ross, E. (1969) On Death and Dying, Routledge, ISBN 0-415-04015-9

Leonova, M. , Ballard, G. \& Gehbauer, F. 2017, 'Strategies That Can Help Transform the Construction Industry' In:, 25th Annual Conference of the International Group for Lean Construction. Heraklion, Greece, 9-12 Jul 2017. pp 333-340

Manders, B., 2015. Implementation and Impact of ISO 9001(No. EPS-2014-337-LIS).

Moore, G. A. (1991). Crossing the chasm: marketing and selling technology products to mainstream customers. [New York, N.Y.], HarperBusiness.

Naney, D. , Goser, C. \& Azambuja, M. 2012, 'Accelerating the Adoption of Lean Thinking in the Construction Industry' In:, Tommelein, I.D. \& Pasquire, C.L., 20th Annual Conference of the International Group for Lean Construction. San Diego, USA, 18-20 Jul 2012. 
Nesensohn, C. , Bryde, D. , Ochieng, E. , Fearon, D. \& Hackett, V. 2014, 'Assessing Lean Construction Maturity' In:, Kalsaas, B.T., Koskela, L. \& Saurin, T.A., 22nd Annual Conference of the International Group for Lean Construction. Oslo, Norway, 25-27 Jun 2014. pp 1157-1168

Nesensohn, C. , Bryde, D. \& Pasquire, C. 2015, 'A Measurement Model for Lean Construction Maturity' In:, Seppänen, O., González, V.A. \& Arroyo, P., 23rd Annual Conference of the International Group for Lean Construction. Perth, Australia, 29-31 Jul 2015. pp 652-660

Pekuri, A. , Herrala, M. , Aapaoja, A. \& Haapasalo, H. 2012, 'Applying Lean in Construction - Cornerstones for Implementation' In:, Tommelein, I.D. \& Pasquire, C.L., 20th Annual Conference of the International Group for Lean Construction. San Diego, USA, 18-20 Jul 2012.

Pekuri, A. , Pekuri, L. \& Haapasalo, H. 2014, 'Lean as a Business Model' In:, Kalsaas, B.T., Koskela, L. \& Saurin, T.A., 22nd Annual Conference of the International Group for Lean Construction. Oslo, Norway, 25-27 Jun 2014. pp 51-60

Sainath, Y. , Varghese, K. \& Raghavan, N. 2018, 'Framework for Progressive Evaluation of Lean Construction Maturity Using Multi-Dimensional Matrix' In:, 26th Annual Conference of the International Group for Lean Construction. Chennai, India, 18-20 Jul 2018. pp 358-369

Torp, O. , Knudsen, J.B. \& Rønneberg, I. 2018, 'Factors Affecting Implementation of Lean Construction' In:, 26th Annual Conference of the International Group for Lean Construction. Chennai, India, 18-20 Jul 2018. pp 1261-1271

Vrijhoef, R. \& Koskela, L. (2005), 'Revisiting the Three Peculiarities of Production in Construction' In:, 13th Annual Conference of the International Group for Lean Construction. Sydney, Australia, 19-21 Jul 2005. pp 19-27

Ward, S.A., 2015. Critical Success Factors for Lean Construction (Doctoral dissertation, The University of Dundee). 